\title{
Mechanical properties of kenaf fibre thermoplastic polyurethane-natural rubber composites
}

\begin{abstract}
ABSTRCT
Thermoplastic polyurethane-natural rubber TPUR-NR composites filled with treated and untreated kenaf fiber as filler were prepared at different TPUR and NR contents. The content of kenaf fiber was maintained at $12.5 \mathrm{wt} \%$ and the fiber was treated with $6 \%$ solution of sodium hydroxide $(\mathrm{NaOH})$, then dried for 24 hours in $100{ }^{\circ} \mathrm{C}$, hot blended with polymer components, pulverized and pressed. The mechanical properties of the composites such as tensile, flexural and impact strength were determined, and their dependence on $\mathrm{NaOH}$ treatment of kenaf fibers was investigated. The analysis using scanning electron microscope (SEM) was implemented to identify the effect of alkali treatment on the microstructure of kenaf fiber and TPUR-NR composites. An improvement of fiber surface roughness and bonding between the fiber and polymer as well as an increase in impact energy and elongation at break of the composites was observed.
\end{abstract}

Keyword: Thermoplastic polyurethane-natural rubber TPUR-NR; Kenaf fiber; Microstructure. 